\title{
ethic@ \\ UM FUNDAMENTO IMPOSSÍVEL - A LEITURA DE ERNST TUGENDHAT DA ÉTICA SCHOPENHAUERIANA
}

\section{ERNST TUGENDHAT'S ETHICS LESSONS AND HIS READING OF THE SCHOPENHAUERIAN ETHICS}

FELIPE DOS SANTOS DURANTE ${ }^{1}$

(UFAC/Brasil)

\begin{abstract}
RESUMO
Este artigo tem por objetivo, a partir da leitura crítica do texto Vorlesungen über Ethik (Lições Sobre Ética) de Ernst Tugendhat (1930-), e de textos do filósofo Arthur Schopenhauer (1788-1860) - em especial sua principal obra Die Welt als Wille und Vorstellung ( $O$ Mundo como Vontade e Representação) e do escrito não premiado Über der Grundlage der Moral (Sobre o Fundamento da Moral) -, avaliar a leitura e a interpretação de Tugendhat sobre o fundamento da moral schopenhaueriana, explicitando os motivos de afastamento do primeiro em relação ao segundo.
\end{abstract}

Palavras-chave: Ernst Tugendhat; Arthur Schopenhauer; Fundamento da Moral.

\begin{abstract}
This article aims to show, based on the critical reading of the book Vorlesungen über Ethik, by Ernst Tugendhat (1930-) and the texts by the philosopher Arthur Schopenhauer (1788-1860) - in particular his main work Die Welt als Wille und Vorstellung and his text about the Ethics, Über der Grundlage der Moral -, evaluate Tugendhat's reading and interpretation of the foundation of Schopenhauer's morality. We will be able to explain the reasons for Tugendhat's refusal of Schopenhauer's theory of moral.
\end{abstract}

Keywords: Ernst Tugendhat; Arthur Schopenhauer; Basis of Morality.

\section{Introdução}

Ernst Tugendhat (1930-) empreende em seu livro Vorlesungen über Ethik(Lições Sobre Ética) (TUGENDHAT, 1993) um rigoroso exame acerca das condições de possibilidade e plausibilidade da fundamentação da moral, construindo suas teses em diálogo com os principais 
sistemas ético-morais da história da filosofia ocidental. Ao levar em consideração os problemas desta empreitada de se fundamentar universalmente a moral, o autor se lança a um esforço de ampliação dos horizontes de uma reflexão ética que possa ser considerada contemporânea, o que envolve, por exemplo, questões como direitos dos animais, a questão dos nascituros, e a questão dos direitos humanos.

O livro é composto de quinze lições fictícias sobre ética de modo a abordar questões pertinentes da história da filosofia e sistematizar a exposição de cada uma delas. Nas primeiras cinco lições, Tugendhat expõe uma concepção de ética em que fica explícita ao leitor a intenção de tornar plausível o conceito kantiano de moral. Nas lições seguintes - da sexta até a décima - o autor critica várias abordagens éticas existentes na história da filosofia e expõe os motivos pelos quais, segundo ele, elas não podem ser sustentadas no interior de seu projeto ético. Nas lições de número seis, sete, e oito, ele aponta razões formais para as suas críticas; nas lições nove e dez, razões de conteúdo. Já nas lições seguintes e finais, toma como ponto de partida a análise de temas importantes relativos à ética para, então, realizar uma leitura e argumentação originais dos problemas colocados. Eis, em suas linhas mais gerais, a estrutura do curso de ética proposto pelo autor.

\section{Um fundamento impossível}

Um dos embates realizados por Tugendhat sobre o conteúdo das diversas éticas aventadas durante a história do ocidente se dá com o sistema schopenhaueriano, ${ }^{2}$ cuja ética da compaixão é matéria de escrutínio do nono capítulo de seu livro; esse capítulo aborda não só o texto schopenhaueriano, tomando-o como principal expoente dessa vertente, mas também questões éticas relativas aos animais, crianças, e nascituros - ou, em tradução literal, da vida não nascida (o capítulo é intitulado Die Mitleidsethik, Tiere, Kinder, ungeborenes Leben).

A partir da análise do texto Über die Grundlage der Moral (Sobre o Fundamento da Moral) - e não de Die Welt als Wille und Vorstellung ( $O$ Mundo como Vontade e Representação) -, ${ }^{3}$ Tugendhat argumenta em favor de uma posição segundo a qual o conceito schopenhaueriano de moral não é plausível e nem mesmo moral, sendo diametralmente oposto à ética kantiana pelo fato de ter como base para a argumentação um sentimento, um afeto (Affekt) (TUGENDHAT, 1993 p. 177; 1996, p. 191), a saber, a compaixão (Mitleid). ${ }^{4}$ Apesar 
disso, segundo o autor, Schopenhauer faz uma importante contribuição para o debate e reflexão contemporâneos: a moral schopenhaueriana englobaria, também, os animais.

Por que o conceito schopenhaueriano não seria plausível e nem mesmo moral? O autor enxerga nas duas máximas do agir moral schopenhaueriano, neminem laede (não prejudicar o outro) e omnes, quantum potes, iuva, (ajude a todos o quanto puder), uma estreita relação com a regra que, para ele, constitui o núcleo comum de todos os conceitos morais, a saber, a regra de ouro (TUGENDHAT, 1993, p. 67; 1996, p. 71): não faça aos outros o que não queira que façam a você.

É precisamente na regra de ouro que Tugendhat encontra elementos para refletir sobre a moral. ${ }^{5}$ A moral baseada no respeito universal e igualitário seria uma pretensão plausível para a efetivação do ser humano capaz de cooperação, o qual está intimamente relacionado à concepção de Tugendhat sobre o que seria um ser humano bom, justamente aquele que é parceiro de cooperação. O comportamento moral consiste, para ele, em reconhecer o outro como sujeito de direitos iguais (TUGENDHAT, 1993, p. 336; 1996, p. 363). Ele reivindica, assim, a moral do respeito universal e igualitário como ponto de partida seguro para a reflexão sobre temas morais.

É possível entender a aproximação realizada pelo autor entre a teoria schopenhaueriana e a regra de ouro a partir da explicação analítica que ele fornece ao escrutinar esse segundo conceito. Segundo Tugendhat, é possível dividir as regras que resultam da regra de ouro em três grupos: (i) as regras de não prejudicar os outros (die Regeln, anderen nicht zu schaden), que são regras de obrigações negativas, i.e., regras de não fazer certas coisas; (ii) as regras de ajudar aos outros (die Regeln, anderen zu helfen), i.e., as regras de obrigações positivas; e (iii) as regras especificamente cooperativas (die spezifisch kooperativen Regeln), como, sobretudo, as de não mentir e de não faltar com suas promessas - as quais são comumente incluídas nas regras negativas (TUGENDHAT, 1993, p. 73; 1996, p. 78-79).

Entretanto, no confronto entre a norma do respeito (kantiana) e a norma do não prejudicar o outro (schopenhaueriana), Tugendhat acaba por concluir que a primeira possui um alcance maior que a segunda, servindo melhor aos seus propósitos. Nesse ponto é necessário refletir: sob quais condições, sob quais pressupostos, e com quais objetivos, essa conclusão é lícita ou possível? 
Para Tugendhat, o princípio kantiano fornece, diferentemente do princípio schopenhaueriano, critérios para decidir sobre a moralidade ou não de uma ação. Aqui apontamos o que parece ser uma interpretação não acertada acerca da filosofia schopenhaueriana. De fato, como Tugendhat nota, o princípio schopenhaueriano da compaixão fixado na máxima neminem laede - não prejudicar o outro - não oferece um critério de ponderação. Mas isso não ocorre por uma limitação de alcance, e sim porque o princípio da compaixão, tal como formulado por Schopenhauer, jamais poderia servir a esse papel. $\mathrm{O}$ critério de ponderação para Schopenhauer é a consciência moral (Gewissen), ${ }^{6}$ de forma a posteriori, a partir das sensações causadas no sujeito pela ação por ele praticada. A máxima neminem laede não é uma prescrição do como se deve agir; para a filosofia schopenhaueriana ela funciona como uma descrição, uma espécie de rótulo, uma classificação, de uma ação moral já ocorrida, da qual a veracidade - i.e., se a ação realizada foi realmente efetuada com base no sentimento de compaixão - é insondável.

Um segundo ponto da interpretação de Tugendhat a ser colocado em xeque refere-se à seguinte passagem:

\begin{abstract}
As duas dificuldades [alcance limitado e a falta de um critério de ponderação] também mostram que o princípio de Schopenhauer (como então naturalmente também sua concepção de motivação) é completamente sem serventia para uma ética política. $\mathrm{Na}$ ética política, trata-se quase sempre de ter que ponderar entre os interesses de muitos (vários); trata-se além disso de direitos, os quais novamente são pressupostos, ao se afirmar que alguém sofre quando estes não lhe são garantidos; assim, por exemplo, no direito à participação política (TUGENDHAT, 1993, p. 181; 1996, p. 194). ${ }^{7}$
\end{abstract}

Tal afirmação desconsidera o potencial e a abrangência da filosofia de Schopenhauer: para além das indicações textuais sobre o assunto, são notáveis a recepção e o desenvolvimento da filosofia do autor no que se refere à filosofia prática, principalmente pela chamada esquerda schopenhaueriana ${ }^{8}$ e por autores como, por exemplo, Alfred Schmitt e Max Horkheimer. ${ }^{9}$ É preciso salientar, também, que todas as questões éticas relacionadas à política na obra schopenhaueriana ocorrem e são referidas no registro do egoísmo, não no registro da compaixão, o que foge do escopo da fundamentação de Tugendhat. Este procura e persegue uma fundamentação moral para a práxis política; Schopenhauer oferece o âmbito da amoralidade, do egoísmo, e do cálculo racional de utilidade individual para apenas descrever, analisar, e explicar as questões referentes à política. 
A argumentação de Tugendhat acaba por adotar certa dose de sarcasmo e ironia, exprimindo, de forma negativa, a seguinte afirmação acerca da filosofia de Schopenhauer: "Se julgamos como moral uma ação boa ou a abstenção de uma má somente quanto ela ocorre por compaixão, então parece resultar daí que somente podem ser morais, quanto ao conteúdo, aqueles tipos de ações que ocorrem por este motivo" (TUGENDHAT, 1993, p. 181; 1996, p. 195). ${ }^{10}$ Todavia, o sarcasmo e a ironia são utilizados em referência a uma afirmação que do ponto de vista da filosofia schopenhaueriana é precisa e correta. Tugendhat prossegue: "Existem certamente seres humanos que, diante de qualquer sofrimento, reagem espontaneamente com compaixão, mas a maioria faz isto apenas parcialmente, e em alguns existe, mais forte do que a compaixão, o seu sentimento contrário da alegria maligna, e o prazer na crueldade" (TUGENDHAT, 1993, p. 182; 1996, p. 196). ${ }^{11}$

Também essa afirmação é precisa e correta. A compaixão não é a motivação principal para as ações realizadas e ela responde em diferentes graus - com maior ou menor intensidade - de acordo com a disposição particular do caráter inteligível de cada indivíduo. Em Schopenhauer, portanto, não é possível extrair uma regra constante e universal de como e em que grau a compaixão influencia as ações dos indivíduos, sendo apenas possível afirmar que uma ação que decorre de uma motivação compassiva é moral, mas sem a possibilidade de sondar e afirmar categoricamente que a compaixão foi a responsável mesma, a causa e motivação, da ação praticada.

Ademais, no que se refere às dificuldades e impedimentos encontrados por Tugendhat quanto à plausibilidade de fundamentação da moral a partir da filosofia schopenhaueriana e seu conteúdo, o autor das Lições Sobre Ética busca um fundamento para a moral que obrigue, o que parece ser o ponto nevrálgico do não enquadramento de Schopenhauer no programa ético vislumbrado por Tugendhat: "Pode afinal um tal sentimento, naturalmente pré-dado e existente em graus diversos, ser o fundamento para uma obrigação? Somos nós obrigados por compaixão?" (TUGENDHAT, 1993, p. 183; 1996, p. 196). ${ }^{12}$

É um tanto trivial para o leitor que acompanha de forma consequente a argumentação schopenhaueriana que o sentimento de compaixão não pode ser o fundamento de uma obrigação no sentido empregado por Tugendhat.

O autor mais uma vez afirma sarcasticamente que "não podemos extrair magicamente nada de universal e de normativo da compaixão" (TUGENDHAT, 1993, p. 186; 1996, p. 200); ${ }^{13}$ 
Schopenhauer estaria de acordo com tal afirmação, porque sua filosofia não trata a motivação da compaixão como fator universal determinante - a compaixão não é a motivação recorrente e predominante do agir humano nos mesmos termos empregados por Tugendhat, senão poderse-ia afirmar a partir da própria filosofia schopenhaueriana que esse não é o pior dos mundos possíveis; ela vai justamente de encontro à normatividade. Uma moral do respeito universal, nesses termos, exigiria que cada um de nós nos comportássemos universalmente de modo éticocompassivo, ou que cada um de nós escolhêssemos nos comportar assim, o que, como é bem explícito, não são possibilidades admissíveis a partir das premissas enunciadas pela filosofia schopenhaueriana. ${ }^{14}$

\section{Conclusão}

Schopenhauer, dessa forma, não cumpre diversos requisitos exigidos na proposta de fundamentação da moral empreendida por Ernst Tugendhat, estando em desacordo com uma série de fatores centrais para o filósofo analítico. Podemos, assim, elencar sete limitações do conceito de compaixão schopenhaueriano: (i) o conceito de compaixão não é a base do respeito universal e igualitário; (ii) ele possui um alcance limitado; (iii) ele não serve como critério puro de ponderação para a classificação de uma ação como moralmente boa ou má - o critério, para Schopenhauer, é a consciência moral (Gewissen); (iv) ele não nos obriga (verpflichtet) em relação uns aos outros, i.e., ele não pode ser entendido de modo normativo e não torna os seres humanos parceiros de cooperação; ${ }^{15}$ (v) ele não serve à filosofia ético-política, tal como entendida por Tugendhat; (vi) ele é um sentimento "pré-dado" existente em diversos graus; e (vii) ele não é a principal e recorrente motivação que causa o agir humano.

Dessa forma, Tugendhat, que não é simplesmente um comentador de Arthur Schopenhauer, acaba por afastar o fundamento moral apresentado por Schopenhauer como uma possibilidade plausível para o seu próprio sistema ético, dado que a moral da compaixão schopenhaueriana, como foi possível constatar ao longo desse texto, não pôde ser moldada e adaptada às necessidades e à proposta apresentada pelo filósofo analítico. Isso significa que a moral da compaixão schopenhaueriana não atende os critérios apresentados pelo autor. Logo, do ponto de vista de uma exegese estrita da filosofia schopenhaueriana, i.e., desconsiderando os pressupostos e os objetivos assumidos por Tugendhat em suas Lições Sobre Ética, a leitura 
de Schopenhauer feita pelo filósofo analítico seria alvo de consideráveis objeções, tal como de inconsistências - as quais apontamos ao longo do nosso texto. 


\title{
Notas:
}

${ }^{1}$ Professor Adjunto da Universidade Federal do Acre (UFAC), Rio Branco, AC., Brasil. E-mail: felipedurantex@gmail.com

2 Adotou-se a edição das obras completas em alemão organizadas por Paul Deussen (SCHOPENHAUER, 19111942). A tradução adotada de Die Welt als Wille und Vorstellung para uma leitura cotejada com a obra em idioma alemão foi feita por Jair Lopes Barboza (SCHOPENHAUER, 2005).

Para a obra Über die Grundlage der Moral adotou-se a tradução brasileira intitulada Sobre o fundamento da moral de Maria Lucia Mello Oliveira Cacciola (SCHOPENHAUER, 2001), de modo que após a indicação da página desta tradução, traremos também o tomo e a paginação referentes à edição alemã. Para leitura de Über die Freiheit des Willens, adotou-se a tradução espanhola de Pilar López de Santa María contida no livro Los dos problemas fundamentales de la ética (SCHOPENHAUER, 2007). Para a leitura da obra Parerga und Paralipomena adotouse as traduções brasileiras do professor Flamarion Caldeira Ramos presentes em Sobre a filosofia e seu método (SCHOPENHAUER, 2010) e em Sobre a ética (SCHOPENHAUER, 2012, cap. VIII-XV) - também em relação a estas, apresentaremos o tomo e paginação da edição alemã e, após cada citação, traremos em nota os excertos utilizados em seu idioma original.

\begin{abstract}
${ }^{3}$ Schopenhauer é conhecido como autor de um sistema único, expresso em sua principal obra, O Mundo como Vontade e Representação. Todas as suas demais publicações, como o próprio filósofo explica, são complementos, adendos e novas formas de exposição sobre o conteúdo desse texto basilar. Era de se esperar que esta obra fosse utilizada como fonte para o debate, em especial o seu quarto livro - que versa justamente sobre a ética. Contudo, é facilmente compreensível o fato de Tugendhat ter selecionado um texto específico sobre o fundamento da moral para a sua análise, dado que o próprio Schopenhauer afirma que não existem discrepâncias entre os textos. Entre os exegetas da filosofia schopenhaueriana essa posição não é tão pacífica: por possuírem pontos de vista expositivos diversos, é possível localizar diferenças que podem ocasionar divergências. Segundo afirmação de Schopenhauer no primeiro prefácio da obra Os Dois Problemas Fundamentais da Ética (Die beiden Grundprobleme der Ethik), na qual o filósofo reúne dois de seus textos, Sobre a Liberdade da Vontade (Über die Freiheit des Willens) e Sobre o Fundamento da Moral (Über die Grundlage der Moral): "São propriamente explicações especiais de duas doutrinas, as quais em seus traços principais são encontradas no quarto livro de $O$ Mundo como Vontade e Representação, mas enquanto naquela obra são deduzidas a partir da minha metafísica, ou seja, de modo sintético e a priori; nesta, pelo contrário, onde à questão não foi permitido nenhum pressuposto, fundamenta-se tais explicações de forma analítica e a posteriori: por isso o que foi ali o primeiro, aqui será o último.” (SCHOPENHAUER, 1911-1942, III, p. 433). No original alemão: „Es sind eigentlich specielle Ausführungen zweier Lehren, die sich, den Grundzügen nach, im vierten Buche der »Welt als Wille und Vorstellung « finden, dort aber aus meiner Metaphysik, also synthetisch und a priori abgeleitet wurden, hier hingegen, wo, der Sache nach, keine Voraussetzungen gestattet waren, analytisch und a posteriori begründet auftreten: daher was dort das Erste war, hier das Letzte ist.“
\end{abstract}

\footnotetext{
${ }^{4}$ A palavra compaixão é uma das possíveis traduções para a palavra alemã Mitleid, cuja tradução literal para o português seria "padecer / sofrer com". Para Schopenhauer, a compaixão é a motivação moral por excelência porque ela tem como finalidade o bem-estar alheio e porque o sofrimento do outro se torna o motivo do agente. É nela onde o filósofo identifica o amor puro - "Todo amor (ágape, caritas) é compaixão” [,Alle Liebe ( $\alpha \gamma \alpha \pi \eta$, caritas) ist Mitleid"] (SCHOPENHAUER, 2005, p. 476, §66, I 443) e "Todo amor puro é compaixão” [„Alle reine Liebe ist Mitleid"] (SCHOPENHAUER, 2005, p. 478, §67, I 444). Ela consiste em graus de olhar através (Durchschauen) do princípio de individuação que permitem conhecer e reconhecer a identidade da essência metafísica do mundo como unidade, i.e., reconhecer que a diferença entre o eu e o outro é mera aparência. Mas não se trata de apenas reconhecer a identidade da essência metafísica entre si mesmo e os outros. É preciso o conhecimento intuitivo, cuja expressão é afetiva: o sentimento de compaixão.
} 
${ }^{5} \mathrm{Na}$ quinta lição de seu livro, Tugendhat localiza na segunda figura do imperativo categórico kantiano- "Age de tal maneira que use a humanidade, tanto na tua pessoa como na pessoa de qualquer outro, sempre e simultaneamente como fim e nunca simplesmente como meio" -, que ele interpreta como "não instrumentalize ninguém", o conteúdo da moral, afirmando que "esta concepção pode ser denominada como a moral do respeito universal” (TUGENDHAT, 1993, p. 80; 1996, p. 87). A segunda figura do imperativo é elaborada em Kant (1986, p.69). No original: „Handle so, daß du die Menschheit sowohl in deiner Person, als in der Person eines jeden andern jederzeit zugleich als Zweck, niemals bloß als Mittel brauchst“. Sobre as figuras do imperativo categórico ver Paton (1971).

${ }^{6}$ A consciência moral, para Schopenhauer, é uma espécie de atributo dos seres dotados de razão responsável por emitir juízos sobre o valor moral de certos atos individuais determinados. Por mais que o indivíduo esteja envolto no princípio de individuação, segundo Schopenhauer, no mais íntimo de sua consciência, o indivíduo tem o pressentimento de que o mundo empírico é mero fenômeno, mera aparência. Quem pratica a injustiça sente que quem sofre a injustiça é igual a ele em essência, sente que o outro e ele são ambos um esforço de autoconservação e que ele, o praticante da injustiça, nesse caso, é mais forte.

Esse sentimento (Gefühl) do injusto é a consciência moral, a qual também é conhecida por foro íntimo e por tribunal interno, e é justamente a tomada de consciência por parte do indivíduo do sentido ético da ação praticada por ele mesmo: "o saber do indivíduo sobre aquilo que fez” [,Es ist das Wissen des Menschen um Das, was er gethan hat"] (SCHOPENHAUER, 2001, p. 87, III 640); a consciência moral pode ser entendida como um tipo de reconhecimento (Erkenntnis), porém um reconhecimento não teórico, um reconhecimento sentido, uma espécie de sentimento, podendo ser considerada como a expressão emocional sensível do conhecimento que temos do significado moral de nossas ações.

Sobre a consciência moral ser a tomada de consciência do sentido ético da ação, pode-se ler em Schopenhauer (2005, p. 456, §64, I 422): "Mas, a partir de nossa exposição não mítica porém filosófica da justiça eterna, queremos agora passar à consideração que lhe é aparentada do significado ético da ação e consciência moral, que não passa do mero conhecimento sentido desse significado.” No original alemão: „Aber von unserer nicht mythischen, sondern philosophischen Darstellung der ewigen Gerechtigkeit wollen wir jetzt zu den dieser verwandten Betrachtungen der ethischen Bedeutsamkeit des Handelns und des Gewissens, welches die bloß gefühlte Erkenntniß jener ist, fortschreiten.“

${ }^{7}$ No original alemão: „Beide Schwierigkeiten zeigen auch, daß Schopenhauers Prinzip (wie dann natürlich auch seine Auffassung von der Motivation) für eine politische Ethik vollständig unbrauchbar ist. In der politischen Ethik geht es fast immer darum, zwischen den Interessen mehrerer abwägen zu müssen, und außerdem um Rechte, die zum Teil wiederum vorausgesetzt werden müssen, wenn behauptet wird, daß jemand, dem sie nicht gewährt werden, daran leidet, so z.B. beim Recht auf politische Partizipation.“

${ }^{8}$ A respeito desse ponto, conferir Lütkhaus (1980; 2007) e Durante (2018).

9 É emblemática, nesse contexto, a seguinte citação de Horkheimer: "Os dois filósofos que influenciaram de maneira decisiva o nascimento da Teoria Crítica foram Schopenhauer e Marx” (HORKHEIMER, 1985, p. 336). No original em alemão: „Die Beiden Philosophen, welche die Anfänge der Kritischen Theorie entscheidend beeinflußt haben, waren Schopenhauer und Marx.“

${ }^{10}$ No original alemão: „Wenn wir eine gute Tat der die Enthaltung von einer schlechten nur dann als moralisch beurteilen, wenn sie aus Mitleid geschieht, dann scheint zu folgen, daß auch nur diejenigen Handlungstypen inhaltlich gut sein können die aus dieser Motivation folgen.“

11 Tradução alterada. No original alemão: „Es gibt wohl Menschen, die jedem Leid gegenüber spontan mit Mitleid reagieren, aber die meisten tun das nur partiell, und bei manchen ist der umgekehrte Affekt der Schadenfreude und der Freude an Grausamkeit stärker vorhanden als das Mitleid.“

12 No original alemão: „Kann denn aber ein solches natürlich vorgegebenes und in verschiedenen Graden vorhandenes Gefühl überhaupt Grundlage für ein Verpflichtetsein sein? Sin wir verpflichtet zum Mitleid?“" 
13 No original alemão: ,[...] aber man kann aus ihm selbst [Mitleid] nichts Universelles und Normatives herauszaubern.“

${ }^{14}$ Sobre o determinismo do agir humano ver Schopenhauer (2005, §55; 2007). Essa questão não é tão explícita em Schopenhauer (2001) quanto nos outros textos aludidos.

${ }^{15}$ Não, ao menos, no sentido em que Tugendhat entende cooperação. Importante lembrar que a sociabilidade é explicada por Schopenhauer através do Tédio (Langeweile), o qual faz seres que não se amam - os humanos procurarem uns aos outros (SCHOPENHAUER, 2005, p. 403, §57, I 369). É também conhecida, sobre esse assunto, a fábula (Fabel) dos porcos espinhos: "Em um dia frio de inverno, um grupo de porcos-espinhos apinhase de modo bem próximo para que através do calor recíproco possam se proteger de morrer de frio. Contudo, rapidamente eles sentem os espinhos uns dos outros, motivo pelo qual, então, eles novamente se afastam uns dos outros. Quando a necessidade de aquecimento os traz novamente para perto uns dos outros, repete-se uma segunda vez aquele mal, de modo que eles iam daqui para lá passando por ambos os sofrimentos, até que eles encontrassem uma distância mediana na qual eles pudessem melhor se suportar. - Da mesma forma surge a necessidade da sociedade, nascida do vazio e da monotonia do próprio interior, os seres humanos são impelidos uns aos outros; mas as suas muitas características repugnantes e erros insuportáveis os fazem se rejeitar. A distância mediana, que eles finalmente encontram, e pela qual pode-se manter um convívio, é a cortesia e os bons costumes. A aquele que não mantém essa distância se diz na Inglaterra: keep your distance! (mantenha distância!) - Em virtude disso, a necessidade de aquecimento recíproca é satisfeita inadequadamente, mas a picada do espinho não é sentida. Quem, contudo, possui em seu interior muito calor próprio, permanece com prazer fora da sociedade para evitar assim fazer e receber reclamações” (SCHOPENHAUER, 1911-1942, V, §396, p. 717). No original alemão: „Eine Gesellschaft Stachelschweine drängte sich, an einem kalten Wintertage, recht nahe zusammen, um durch die gegenseitige Wärme, sich vor dem Erfrieren zu schützen. Jedoch bald empfanden sie die gegenseitigen Stacheln; welches sie dann wieder von einander entfernte. Wann nun das Bedürfniß der Erwärmung sie wieder näher zusammen brachte, wiederholte sich jenes zweite Uebel; so daß sie zwischen beiden Leiden hin und hergeworfen wurden, bis sie eine mäßige Entfernung von einander herausgefunden hatten, in der sie es am besten aushalten konnten. - So treibt das Bedürfniß der Gesellschaft, aus der Leere und Monotonie des eigenen Innern entsprungen, die Menschen zu einander; aber ihre vielen widerwärtigen Eigenschaften und unerträglichen Fehler stoßen sie wieder von einander ab. Die mittlere Entfernung, die sie endlich herausfinden, und bei welcher ein Beisammenseyn bestehn kann, ist die Höflichkeit und feine Sitte. Dem, der sich nicht in dieser Entfernung hält, ruft man in England zu: keep your distance! - Vermöge derselben wird zwar das Bedürfniß gegenseitiger Erwärmung nur unvollkommen befriedigt, dafür aber der Stich der Stacheln nicht empfunden. - Wer jedoch viel eigene, innere Wärme hat bleibt lieber aus der Gesellschaft weg, um keine Beschwerde zu geben, noch zu empfangen." 


\section{Referências Bibliográficas}

DURANTE, F. A esquerda schopenhaueriana no Brasil. Voluntas: Revista Internacional de Filosofia, [S.1.], v. 9, n. 1, p. 137-147, jul. 2018. ISSN 2179-3786. Disponível em: $<$ https://periodicos.ufsm.br/voluntas/article/view/33548>. Acesso em: 25 set. 2018. doi:http://dx.doi.org/10.5902/2179378633548.

HORKHEIMER, M. Kritische Theorie gestern und heute. In: Gesammelte Schriften. Org. A. Schmidt. Frankfurt: Fischer Taschenbuch Verlag, 1985.

KANT, I. Fundamentação da metafísica dos costumes. Tradução de Paulo Quintela. Lisboa: Edições 70, 1986.

LÜTKEHAUS, L. Einleitung II: Pessimismus und Praxis. Umrisse einer kritischen Philosophie des Elends. In: EBELING, H.; LÜTKEHAUS, L (Orgs.). In: Schopenhauer und Marx: Philosophie des Elends - Elend der Philosophie?. Herausgegeben und eingeleitet von Hans Ebeling und Ludger Lütkehaus. Königstein/Ts.: Hain, 1980.

LÜTKEHAUS, L. Esiste una sinistra schopenhaueriana? Ovvero: il pessimismo è un quietismo? In: FAZIO, D.; KOßLER, M.; LÜTKEHAUS, L. (Orgs.). Arthur Schopenhauer e la sua scuola: Per l'inaugurazione del Centro interdipartimentale di ricerca su Arthur Schopenhauer e la sua scuola dell'Università del Salento. A cura di Fabio Ciracì, Domenico M. Fazio, Francesca Pedrocchi. Collana del Centro interdipartimentale di ricerca su Arthur Schopenhauer e la sua scuola dell'Università del Salento diretta da Domenico M. Fazio, Matthias Koßler e Ludger Lütkehaus, Vol. 1. Lecce: Pensa Multimedia, 2007.

PATON, H. J. The categorical imperative. A study in Kant's moral philosophy. Pennsylvania: University of Pennsylvania Press, 1971.

SCHOPENHAUER, A. Arthur Schopenhauers sämtliche Werke. Hrsg. von Paul Deussen. Munique: R. Piper, 1911-1942.

SCHOPENHAUER, A. Sobre o fundamento da moral. Tradução Maria Lucia Mello Oliveira Cacciola. São Paulo: Martins Fontes, 2001.

SCHOPENHAUER, A. O mundo como vontade e como representação. Tradução, apresentação, notas e índices de Jair Barboza. São Paulo: Editora UNESP, 2005. ( $1^{\circ}$ tomo).

SCHOPENHAUER, A. Los dos problemas fundamentales de la ética. Tradução, introdução e notas de Pilar López de Santa María. Madri: Siglo XXI de España Editores, 2007.

SCHOPENHAUER, A. Sobre a filosofia e seu método. Organização e tradução de Flamarion Caldeira Ramos. São Paulo: Hedra, 2010.

SCHOPENHAUER, A. Sobre a ética. Tradução de Flamarion Caldeira Ramos. São Paulo: Hedra, 2012.

STAUDT, L. A descrição do fenômeno moral em Schopenhauer e Tugendhat. ethic@ - An international Journal for Moral Philosophy, Florianópolis, v. 3, n. 2, p. 163-176, jan. 2004. 
ISSN 1677-2954. Disponível em:

$<$ https://periodicos.ufsc.br/index.php/ethic/article/view/14777/13496>. Acesso em: 03 out. 2018. doi:https://doi.org/10.5007/\%x.

TUGENDHAT, E. Vorlesungen über Ethik. Frankfurt: Suhrkamp, 1993.

TUGENDHAT, E. Lições sobre ética. Tradução do grupo de doutorandos do Curso de PósGraduação da UFRGS, revisão e organização da tradução de Ernildo Stein e Ronai Rocha. Petrópolis: Vozes, 1996. 